\title{
Rare case of iridofundal coloboma with buried optic nerve head drusen in a paediatric patient
}

\author{
Nishant Radke, ${ }^{1}$ Charudutt Kalamkar, ${ }^{2}$ Amrita Mukherjee, ${ }^{1}$ Snehal Radke ${ }^{1}$
}

${ }^{1}$ Shri Ganesh Vinayak Eye Hospital, Raipur, Chhattisgarh, India

${ }^{2}$ Department of

Ophthalmology, Shri Ganesh Vinayak Eye Hospital, Raipur, Chhattisgarh, India

\section{Correspondence to}

Dr Charudutt Kalamkar, charudutt03@yahoo.co.in

Accepted 26 July 2016
CrossMark

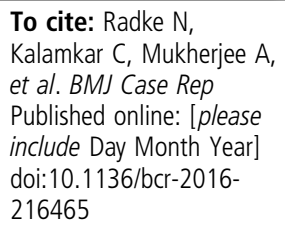

\section{DESCRIPTION \\ Case}

An 8 year-old boy presented with typical iridofundal coloboma (IFC) in the left eye (OS) with buried optic nerve head drusen (ONHD). Right eye (OD) had iris coloboma associated with total cataract and retinal detachment. He did not have any neurological symptoms.

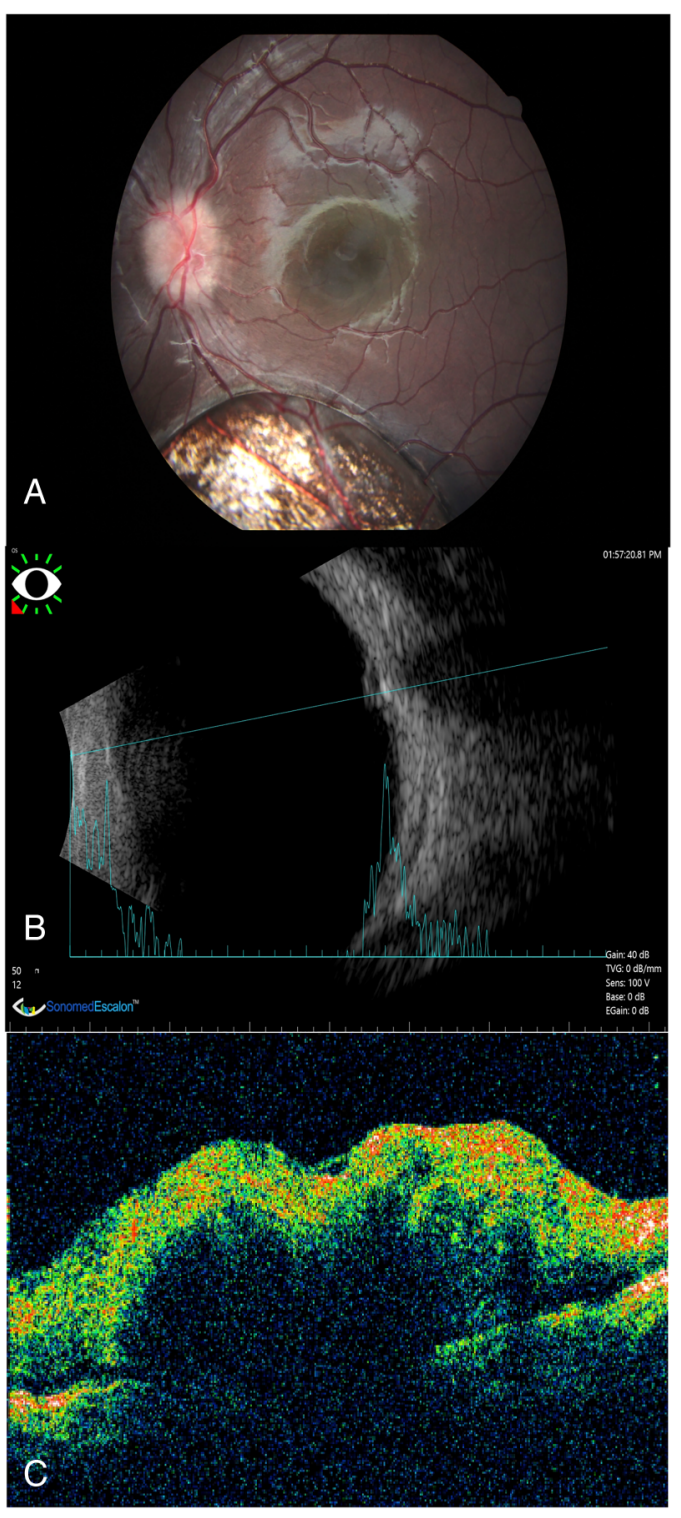

Figure 1 (A) Colour fundus image of the posterior pole showing pseudopapilloedema and macula sparing inferior iridofundal coloboma. (B) B scan through optic nerve head showing elevated soft tissue with a high reflective clump echo underneath having $100 \%$ reflectivity at reduced gain on vector scan. (C) Optical coherence tomography scan through optic nerve head showing multiple focal, hyper-reflective and subretinal masses.
Best-corrected visual acuity in OD was light perception (PL+), OS was 6/6, N6. Posterior segment in OS revealed the presence of a retinochoroidal coloboma. The disc looked elevated with irregular margins with hyperaemic appearance. Venous pulsations were present with normal looking calibre of vessels with a normal peripapillary retina. These features were suggestive of pseudopapilloedema due to ONHD (figure 1A). B-scan ultrasonography (USG) showed hyperechoic material within the optic nerve head with a $100 \%$ spike on a superimposed A-scan persisting even at completely reduced gain (figure 1B). Optical coherence tomography (OCT) demonstrated multiple focal, hyperreflective, subretinal masses within the nerve head (figure 1C). In view of the retinal detachment in $\mathrm{OD}$, prophylactic laser barrage treatment was performed on the extramacular coloboma in OS.

\section{DISCUSSION}

ONHD are proteinaceous excrescences which increase in size and become calcified with time. They result from stasis of axoplasmic flow leading to abnormal axonal metabolism. ONHD are found in up to $0.4 \%$ of paediatric population. In early stages they remain buried and surface in later years. Buried ONHD present as blurring and irregularity of disc margins and are diagnosed by USG, OCT and autofluorescence imaging. ${ }^{1}{ }^{2}$ ONHD are usually asymptomatic but have been shown to cause visual field defects, non-arteritic anterior ischaemic optic neuropathy, haemorrhages, macular nerve fibre layer thinning and form choroidal neovascular membranes. ${ }^{2}$

To the best of our knowledge this rare association of buried ONHD and IFC has been reported only once in the literature.

\section{Learning points}

- Early diagnosis of buried optic nerve head drusen (ONHD) in the paediatric age group would alert the clinicians to look for potential complications at follow-up visits.

- Diagnosis of pseudopapilloedema due to buried ONHD is essential to prevent unnecessary expensive or invasive investigations like MRI or lumbar puncture in paediatric patients.

- This case also demonstrates the importance of imaging modalities such as ultrasonography and optical coherence tomography in diagnosing buried ONHD. 
Contributors NR and CK involved in idea, manuscript preparation, literature search and proof reading. AM and SR involved in manuscript preparation and proof reading.

Competing interests None declared.

Patient consent Obtained.

Provenance and peer review Not commissioned; externally peer reviewed.

\section{REFERENCES}

1 Kurz-Levin MM, Landau K. A comparison of imaging techniques for diagnosing drusen of the optic nerve head. Arch Ophthalmol 1999;117:1045-9.

2 Wilkins JM, Pomeranz HD. Visual manifestations of visible and buried optic disc drusen. J Neuroophthalmol. 2004;24:125-9.

3 Dehghani AR, Rezaei L, Ghanbari H. Bilateral optic nerve head drusen with chorioretinal coloboma in the right eye. Adv Biomed Res 2016;5:34.

Copyright 2016 BMJ Publishing Group. All rights reserved. For permission to reuse any of this content visit http://group.bmj.com/group/rights-licensing/permissions.

BMJ Case Report Fellows may re-use this article for personal use and teaching without any further permission.

Become a Fellow of BMJ Case Reports today and you can:

- Submit as many cases as you like

- Enjoy fast sympathetic peer review and rapid publication of accepted articles

- Access all the published articles

- Re-use any of the published material for personal use and teaching without further permission

For information on Institutional Fellowships contact consortiasales@bmjgroup.com

Visit casereports.bmj.com for more articles like this and to become a Fellow 